\title{
Conserving the African wild dog Lycaon pictus. II. Is there a role for reintroduction?
}

\author{
Rosie Woodroffe and Joshua R. Ginsberg
}

\begin{abstract}
African wild dogs Lycaon pictus have been extirpated across most of West and central Africa, and greatly depleted in eastern and southern Africa. Given an urgent need for population recovery, especially in West and central Africa, this paper discusses the possibilities for using reintroduction to re-establish wild dog populations. Reintroduction is probably now technically possible, as long as release groups include wildcaught animals; several past attempts failed because captive-reared animals lacked skills needed to survive in the wild. However, reintroduction has only a limited role to play in wild dog conservation. Ideally, it should involve animals of the appropriate local genotype. Limited genetic data indicate that wild dogs from West and central Africa may be distinct from those in eastern and southern Africa. Because there are no wild dogs with
\end{abstract}

West or central African genotypes in captivity, and no wild populations in the region large enough to be harvested for translocation, future reintroductions might have to use animals with non-native genotypes. In addition, there appear to be no suitable sites for wild dog reintroduction in West or central Africa, and few in eastern and southern Africa. Releases currently planned in the Republic of South Africa will be locally valuable, but will not establish a population likely to remain viable without intensive management in perpetuity. For these reasons, protecting remaining wild dog populations currently represents a better investment than any attempt at reintroduction.

Keywords Captive breeding, carnivore conservation, conservation genetics, hunting behaviour, translocation.

\section{Introduction}

The African wild dog Lycaon pictus has suffered a serious decline over the last century (Woodroffe \& Ginsberg, 1999). Formerly distributed throughout most of sub-Saharan Africa, wild dogs have been extirpated from 25 of the 39 countries in which they were formerly recorded, and are now virtually extinct in West and central Africa (Woodroffe et al., 1997). At present, only six countries in southern and eastern Africa contain populations that may be viable in the long term. Woodroffe \& Ginsberg (1999) analysed the causes of this decline, and suggested strategies for the conservation of the remaining wild populations. In this paper, we review the possibilities for re-establishing populations in some of the areas from which wild dogs have been extirpated. In particular, we discuss the role that

Rosie Woodroffe (corresponding author) Department of Biological Sciences, University of Warwick, Coventry CV4 7AL, UK. Tel: + 44 (0)1203 524618; fax: + 44 (0)1203 524619;

e-mail: r.b.woodroffe@warwick.ac.uk

Joshua R. Ginsberg Wildife Conservation Society, 2300 Southern Bvd, Bronx, NY 10460-1099, USA. Tel: + 1 (718) 220 5884; fax: + 1 (718) 364 4275; e-mail: jginsberg@wcs.org

Received 18 May 1998. Accepted 1 October 1998 reintroduction might play in wild dogs' population recovery.

Reintroduction has proved a valuable tool for the recovery of species that have become either globally or locally extinct in the wild (Stanley-Price, 1988; Phillips, 1995; Fritts et al., 1997). Past attempts to re-establish extirpated populations have involved the release of both wild-caught and captive-bred animals; we consider both of these to be forms of reintroduction (IUCN, 1995). However, reintroduction is not always an appropriate component of species recovery plans (Kleiman et al., 1994). Biological, logistical, organizational and even legal problems have limited the success of many reintroduction programmes, and, thus far, very few have led to the re-establishment of viable populations in the wild (Griffith et al., 1989; Beck et al., 1994). Recent plans for wild dog recovery within the Republic of South Africa are primarily based upon reintroduction (Mills et al., 1998; Woodroffe, 1998). In the light of these plans, we evaluate the extent to which reintroduction may contribute to future efforts for wild dog conservation both in South Africa and elsewhere.

\section{Where is wild dog reintroduction most needed?}

Reintroductions may be planned to meet several re- 
gional or global goals for wild dog recovery. Releases might be used to increase the number of wild dog populations both globally and locally, reducing the chances of species extinction and also preserving regionally distinct genotypes. Reintroduction might also be a component of habitat restoration, re-establishing wild dogs as predators in ecosystems from which they have been lost.

According to these aims, wild dog reintroduction is most needed in West Africa. Wild dogs' historical distribution covered most of sub-Saharan Africa, but viable populations now remain only in southern Africa and in the southern part of East Africa (Woodroffe et al., 1997). In West and central Africa, wild dogs (and other large predators) have been extirpated over very large areas and the few remaining populations are small and highly threatened (Woodroffe et al., 1997). Limited genetic data suggest that West and central African wild dogs may be genetically distinct from those in southern and eastern Africa (Girman et al., 1993; Roy et al., 1994; Woodroffe et al., 1997). Re-establishment of wild dog populations in West and central Africa therefore has a high priority on both ecological and genetic grounds.

Regional goals for wild dog recovery are rather different. The Republic of South Africa, for example, contains one viable population of free-ranging wild dogs, which inhabits the Kruger National Park and surrounding reserves (Maddock \& Mills, 1994). The national goal for wild dog conservation is to establish a second viable wild dog population (Mills et al., 1998; Woodroffe, 1998). This goal, and the implied recognition of a need for local conservation objectives and action, is to be applauded. However, because South Africa contains no protected areas, apart from Kruger National Park, that contain sufficient suitable habitat to sustain a viable wild dog population, plans have been formulated to meet this goal by releasing wild dogs into a network of small, fenced reserves, to be managed as a metapopulation (Mills et al., 1998; Woodroffe, 1998). Unless the reserves are eventually merged, and the fences removed, this strategy can never lead to the re-establishment of a self-sustaining wild dog population (IUCN, 1995), because the metapopulation will require constant management, in perpetuity, to maintain its demographic and genetic viability (Mills et al., 1998). Thus, the reintroductions planned in South Africa have a high priority for increasing wild dog numbers locally, but a relatively low priority globally because they involve a region (southern Africa) that still contains several relatively large populations in need of conservation funds (Woodroffe et al., 1997).

\section{Is wild dog reintroduction technically feasi- ble?}

Several features of wild dogs' biology suggest that reintroduction might be technically difficult. Past reintroduction attempts have proven problematic when they have involved species with complex social or foraging behaviour (Henshaw et al., 1979; Kleiman, 1989). Furthermore, reintroductions that involve species that come into conflict with people have encountered legal and political problems despite being extraordinarily successful in biological terms (Wyoming District Court, 1997). Fortunately, we can evaluate the likely outcome of future attempts to reintroduce wild dogs by assessing the successes and failures of past efforts.

We are aware of 10 attempts to release wild dogs into the wild, which are summarized in Table 1. None of these releases has led to the establishment of a wild population that is viable in the long term; thus, none can be considered truly successful (Beck et al., 1994; IUCN, 1995). Indeed, most can be considered failures: in nine of the 10 cases there is no evidence that any of the released dogs left descendants in the wild. Nevertheless, the various reasons for these failures carry important lessons for the design of future reintroduction attempts, which may meet with greater success.

Lack of survival skills among wild dogs reared in captivity

In five of the 10 releases, release groups were composed entirely of animals reared in captivity (Table 1). All these releases met with failure, at least in part because the animals lacked skills necessary for survival in the wild. Captive-bred wild dogs released into Klaserie Game Reserve, and into Etosha National Park in both 1978 and 1990, all experienced problems hunting (Scheepers, 1992; Scheepers \& Venzke, 1995; M. De Villiers, pers. comm.). The newly released packs chased wild ungulates instinctively, but showed no co-ordination in their hunting behaviour and experienced extremely low hunting success (Plate 1). Captive-bred wolves Canis lupus released in Alaska were similarly inept at hunting (Henshaw et al., 1979). However, captive-bred female wild dogs acquired hunting skills rapidly when they were released into Madikwe Game Reserve in the company of wildcaught males (Mills et al., 1998; M. Hofmeyr, pers. comm.). Attempts at pre-release training in Klaserie Game Reserve and Etosha National Park met with limited success. Live antelopes (tranquillized at 
Table 1 Ten past releases of African wild dogs

\begin{tabular}{|c|c|c|c|c|}
\hline Release site & Year & Origin & Group composition & Fate \\
\hline $\begin{array}{l}\text { Kalahari Gemsbok NP, } \\
\text { South Africa* }\end{array}$ & 1975 & Wild & $\begin{array}{l}3 \text { adult females } \\
2 \text { adult males }\end{array}$ & Group split and disappeared \\
\hline $\begin{array}{l}\text { Etosha NP, Namibia } \\
\text { (1) }+\end{array}$ & 1978 & Captive & 6 yearlings & Starved or killed by lions within 4 months \\
\hline $\begin{array}{l}\text { Etosha NP, Namibia } \\
\quad(2)+\ddagger\end{array}$ & 1989 & Captive & $\begin{array}{l}2 \text { adult females } \\
2 \text { adult males } \\
1 \text { unknown }\end{array}$ & Killed by lions within 3 months \\
\hline $\begin{array}{l}\text { Etosha NP, Namibia } \\
\text { (3) } \ddagger\end{array}$ & 1990 & Captive & $\begin{array}{l}2 \text { adult females } \\
2 \text { adult males } \\
5 \text { yearling females } \\
2 \text { yearling males }\end{array}$ & Six killed by lions, four died of rabies, one disappeared \\
\hline $\begin{array}{l}\text { Hluhluwe-Umfolozi } \\
\text { Park, South Africa§ }\end{array}$ & $1980-8$ & $\begin{array}{l}12 \text { wild, others } \\
\text { captive }\end{array}$ & $\begin{array}{l}2 \text { adult females } \\
3 \text { adult males } \\
7 \text { yearling females } \\
5 \text { yearling males } \\
4 \text { males unknown age } \\
1 \text { female unknown age }\end{array}$ & $\begin{array}{l}\text { Population still extant, with } 13 \text { dogs present in 1994. Eight } \\
\text { litters produced, but none since } 1993\end{array}$ \\
\hline $\begin{array}{l}\text { Matetsi Safari Area, } \\
\text { Zimbabweq }\end{array}$ & 1986 & Captive & $\begin{array}{l}4 \text { yearling females } \\
5 \text { yearling males }\end{array}$ & Shot on nearby farm \\
\hline $\begin{array}{l}\text { Klaserie GR, South } \\
\text { Africa** }^{* *}\end{array}$ & 1991 & Captive & $\begin{array}{l}2 \text { adult females } \\
6 \text { adult males }\end{array}$ & $\begin{array}{l}\text { Moved out of reserve on to neighbouring farmland and } \\
\text { recaptured }\end{array}$ \\
\hline $\begin{array}{l}\text { Venetia Limpopo NR, } \\
\text { South Africa }+\ddagger \ddagger\end{array}$ & 1992 & Wild & $\begin{array}{l}1 \text { adult female } \\
2 \text { adult males } \\
6 \text { yearling females } \\
5 \text { yearling males }\end{array}$ & $\begin{array}{l}\text { Pups were born after the release, but the pack left the } \\
\text { reserve and was poisoned }\end{array}$ \\
\hline $\begin{array}{l}\text { Madikwe GR, } \\
\text { South Africa§§II }\end{array}$ & 1995 & $\begin{array}{l}3 \text { wild } \\
3 \text { captive }\end{array}$ & $\begin{array}{l}3 \text { adult females } \\
3 \text { adult males }\end{array}$ & $\begin{array}{l}\text { Pack survived initial release and produced two litters; } \\
\text { died of rabies } 2 \text { years after release }\end{array}$ \\
\hline $\begin{array}{l}\text { Tsavo West NP, } \\
\text { KenyaIII }\end{array}$ & 1997 & $\begin{array}{l}4 \text { wild } \\
2 \text { captive }\end{array}$ & $\begin{array}{l}4 \text { adult females } \\
2 \text { yearling males }\end{array}$ & $\begin{array}{l}\text { Radio-collared animals lost after } 8 \text { days; unconfirmed } \\
\text { sightings up to } 6 \text { months after release }\end{array}$ \\
\hline
\end{tabular}

NR, Nature Reserve; NP, National Park; GR, Game Reserve.

Data sources: * Frame \& Fanshawe (1990); † Scheepers \& Venzke (1995); † Scheepers (1992); § Maddock (1992); II Childes (1988);

** M. de Villiers (pers. comm.); †+English et al. (1993); łł van Heerden (pers. comm.); $\S \S$ M. Hofmeyr (pers. comm.); III Mills et al. (1998).

Klaserie Game Reserve) were released into the enclosures prior to release (Scheepers \& Venzke, 1995; M. De Villiers, pers. comm.), but the dogs simply killed these animals by chasing them into the fence of the enclosure (Scheepers \& Venzke, 1995).

All three groups of captive-bred wild dogs released in Etosha National Park suffered predation by lions Panthera leo (Scheepers, 1992; Scheepers \& Venzke, 1995), and those released in Matetsi Safari Area were believed to have been injured by spotted hyaenas Crocuta crocuta (Childes, 1988). In contrast, none of the releases involving wild-caught wild dogs reported problems involving larger carnivores, despite the presence of lions and hyaenas at the release sites.
Reintroduction of swift foxes Vulpes velox in Canada was also hampered by predation; when both wildborn and captive-bred foxes were released, coyotes Canis latrans killed a high proportion of the captivebred animals (Carbyn et al., 1994).

\section{Conflicts with people}

Three wild dog releases were ultimately foiled when the animals came into conflict with people. The last members of the group released in Matetsi Safari Area were shot by a farmer when they approached the butchery of a bordering livestock farm (Childes, 1988). It seems probable that, like the wolves released in Alaska (Henshaw et al., 1979), the captive-reared 


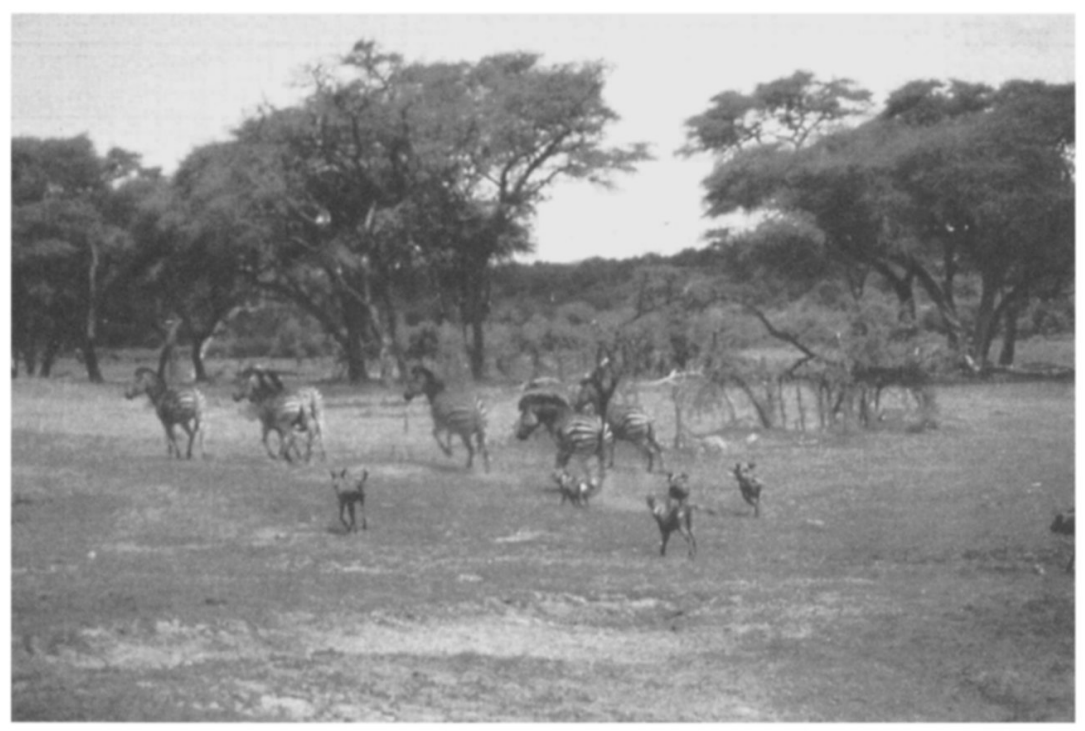

Plate 1 Wild-born African wild dogs, like those shown here, hunt in a co-ordinated manner. Wild dogs reared in captivity often experience low hunting success on release because they lack this co-ordinated behaviour (J.R. Ginsberg).

wild dogs associated humans with food and approached them for this reason. Both the captive-bred group released in Klaserie Game Reserve and the wild-caught pack translocated to Venetia Limpopo Nature Reserve also came into conflict with people when they left the reserves into which they had been released. The Klaserie group moved on to neighbouring farmland and was taken back into captivity; the Venetia pack was apparently poisoned (van Heerden, pers. comm.; M. De Villiers, pers. comm.). The red wolf Canis rufus reintroduction programme, as well as several releases of grey wolves, has experienced similar problems (Weise et al., 1979; Fritts et al., 1985; Phillips, 1995).

\section{Dispersal of animals after release}

The wild dog groups released in the Kalahari, in Klaserie Game Reserve and in Matetsi Safari Area all broke up after release, although the Klaserie group subsequently re-formed (Childes, 1988; Frame \& Fanshawe, 1990; M. De Villiers, pers. comm.). Some relocated grey wolves have shown similar behaviour (Weise et al., 1979), a problem that was rectified by holding the animals in enclosures at the release sites for several months (Fritts et al., 1997). Wild dogs treated in a similar way at Madikwe Game Reserve and Venetia Limpopo Nature Reserve did not disperse (van Heerden, pers. comm.; M. Hofmeyr, pers. comm.), but those released in Tsavo West National Park moved $>40 \mathrm{~km}$ and disappeared within days, despite being held in an enclosure on site prior to release (J. Wambua, pers. comm.).

\section{Disease}

Reintroductions of wild dogs into Madikwe Game Reserve, and into Etosha National Park in 1990, were ultimately foiled when the animals contracted rabies (Scheepers \& Venzke, 1995; Mills et al., 1998). The Etosha wild dogs killed and ate a rabid black-backed jackal Canis mesomelas and died, even though they had been vaccinated against rabies (Scheepers \& Venzke, 1995). The source of infection for the (unvaccinated) Madikwe dogs is unknown, but rabies was confirmed as the cause of death (Mills et al., 1998). Two adults and four yearlings that were captured and vaccinated in an enclosure escaped infection (M. Hofmeyr, pers. comm.).

\section{Summary of release outcomes to date}

No release of wild dogs has led to the establishment of a viable wild population. The only reintroduced population still known to be in existence is the one in Hluhluwe-Umfolozi Park in South Africa. Expansion of this population is limited by the small size of the park (960 sq km). The single pack has not bred since 1993, perhaps because all pack members are now close relatives (Maddock, 1996); a small group of wild dogs were recently released there to supplement this population (M. Somers, pers. comm.). 
Although no long-term viable wild dog populations have been established by reintroduction, the data given above suggest several lessons for future reintroduction attempts. In particular, groups for release should be wild-caught, or composed of a mixture of captive-bred and wild-caught animals, to ensure that they have the skills necessary for survival in the wild. To reduce the risks of post-release dispersal, release groups should be held at the release site for several months. If the release is to involve a newly-formed pack, male and female groups should be introduced to one another early in this pre-release period. Despite past failures, then, it seems probable that wild dog reintroduction could be technically possible, given appropriate choice of reintroduction sites and animals for release.

\section{Are wild dogs available for reintroduction?}

Successful reintroduction depends, in part, upon the choice of individuals to be released (Kleiman, 1989; IUCN, 1995). The first requirement is that the animals released should be those most likely to survive and breed in the wild. As discussed above, successful wild dog reintroduction depends upon the inclusion of at least some wild-caught animals in the release group. A second consideration is that the genotypes of the animals released should be as similar as possible to those of the former population (Kleiman, 1989). Wild dogs show regional variation in genotype (Girman et al., 1993; Woodroffe et al., 1997). Subspecies are no longer recognized, but distinct genotypes exist in southern, eastern and, apparently, West Africa (Roy et al., 1994; Woodroffe et al., 1997). The ideal reintroduction of wild dogs would therefore depend upon the existence of a wild population large enough to be harvested for translocation, of the appropriate local genotype. Wildcaught animals could be supplemented with those bred in captivity; again, provided they were of the appropriate genotype.

According to these criteria, wild dogs are available for release in southern Africa. This region still contains more than one wild population numbering several hundred animals (Woodroffe et al., 1997); population viability analyses indicate that the population in Kruger National Park could sustain harvesting for local reintroduction efforts (Mills et al., 1998). In addition, there are several hundred wild dogs of southern African origin held in captivity, which could be used to supplement wild-caught stock (Brewer \& Rhodes, 1992).

In other regions of Africa, however, future reintroduction attempts may be hindered by a lack of animals suitable for release. In East Africa, there is a large wild dog population in the Selous Game Reserve, which would be large enough to provide animals for translocation; however, this population shares genetic affinities with southern African wild dogs (Woodroffe et al., 1997). Unique East African genotypes were found further north in the population inhabiting the Serengeti-Masai Mara ecosystem, but this population is now extinct (Girman et al., 1993; Woodroffe et al., 1997) and other relict populations in East Africa have not been genotyped. Thus, there may be no free-ranging populations of wild dogs known to carry East African genotypes that are large enough to provide animals for translocation. The only East African wild dogs held in captivity derive from three litters of pups captured in the Maasai steppe by the George Adamson Wildlife Preservation Trust (Fitzjohn, 1995). As far as we are aware, these animals have not been genotyped.

No animals of western genotypes are currently available for release. Neither West nor central Africa contains a wild dog population that is large enough to be harvested without affecting its own viability (Woodroffe et al., 1997), and there are no wild dogs of West or central African origin in captivity (Brewer \& Rhodes, 1992).

For these reasons, future reintroductions in West Africa-and, perhaps, in East Africa-might require the use of animals with non-native genotypes. The extent to which this would be acceptable depends upon the aims of the reintroduction attempt. If suitable release sites were available, it is highly likely that translocating southern African wild dogs to other parts of Africa could meet the ecological goals of reintroduction, namely to restore local predator populations, and to increase the total number of free-ranging wild dogs in Africa. Wild dogs are behaviourally flexible, and it seems unlikely that genetic differences between the regions reflect extreme adaptation to unique ecological conditions. However, releasing animals with non-native genotypes would make little contribution to the preservation of genetic diversity within the species; indeed, if any animals of native genotype remained at the release site, such releases could be detrimental. Despite these concerns, if suitable release sites were available, on ecological grounds alone we would consider releasing nonnative animals to be preferable to no reintroduction at all, provided it could be shown that the indigenous population was truly extinct, and that neither resident nor transient wild dogs were present in the area of the release site. 


\section{Are suitable sites available for wild dog reintroduction?}

\section{Criteria for suitable release sites}

The choice of sites suitable for reintroduction depends upon a number of criteria (Kleiman et al., 1994; IUCN, 1995), of which the most important is that the cause of wild dogs' previous local extinction should have been removed. This criterion carries the implications that a wild dog population was previously present, that it became extinct, and that the reasons for the extinction are known. In practice this criterion would eliminate several of the areas where past releases have taken place. Both the Tsavo West and Kalahari Gemsbok National Parks are probably unsuitable for wild dogs: both parks are large and well protected, yet neither contains a resident wild dog population, even though they are sighted in neighbouring protected and unprotected areas (Woodroffe et al., 1997). Both Matetsi and Klaserie are parts of protected-area complexes with large resident wild dog populations (Woodroffe et al., 1997). Clearly, a more systematic approach is needed in the choice of future reintroduction sites.

Loss of wild dogs from most of sub-Saharan Africa is associated with high human population density (Woodroffe \& Ginsberg, 1999). This points to the ultimate reason for wild dogs' decline; more specifically, habitat loss and persecution remain the most serious threats to the persistence of Africa's remaining wild dog populations (Woodroffe \& Ginsberg, 1999). Persecution outside reserves has a marked impact upon protected populations because wild dogs' wide-ranging behaviour often brings them into contact with human activity beyond the borders of protected areas (Woodroffe \& Ginsberg, 1999). Probably as a result of such 'edge effects', wild dogs have disappeared from reserves smaller than c. $3500 \mathrm{sq} \mathrm{km}$ (Woodroffe \& Ginsberg, 1998); populations large enough to be viable in the long term are likely to require areas in excess of 10,000 sq km (Woodroffe \& Ginsberg, 1999). For this reason, reintroduction attempts are likely to lead to successful re-establishment of viable wild dog populations only if they are carried out in protected areas of $10,000 \mathrm{sq} \mathrm{km}$ or larger. Smaller reserves might prove acceptable if they were securely fenced.

Release sites should carry low risks of mortality for reintroduced animals. Reintroduction projects should therefore avoid sites close to roads with fast-moving traffic because road accidents are a serious threat to wild dogs (Woodroffe \& Ginsberg, 1999). Wild dogs are also threatened by competition with lions and hyaenas. Like wild dogs, these species have been extirpated across large areas of Africa, especially in the West (Nowell \& Jackson, 1996; Woodroffe et al., 1997; Mills \& Hofer, 1998). While the absence of these competitors might favour re-establishment of wild dogs, in practice such areas will often be unsuitable as reintroduction sites. There are two reasons for this. First, extirpation of lions and hyaenas may indicate extreme local intolerance of predators, suggesting that people close to the release site would be likely to persecute wild dogs should they encounter them. Second, loss of large predators from reserves frequently indicates that the prey base has also been lost; this is the case across much of West Africa (Woodroffe et al., 1997; Mills \& Hofer, 1998). Despite these caveats, however, there are areas-such as game-farming regions of southern Africa-where competing predators have been extirpated, yet prey remain abundant. Such areas would represent prime habitat for wild dogs if landowners would tolerate their presence (Mills et al., 1998). In practice, however, it will seldom prove possible to find release sites containing no competing predators, especially because wild dog reintroduction is often seen as a component of ecosystem restoration that also involves the reintroduction of lions and hyaenas (as, for example, at Madikwe; M. Hofmeyr, pers. comm.). In such circumstances, reintroduction may be most successful if wild dogs are released 12 years before the larger predators, giving them time to establish.

A final threat to wild dogs is disease: rabies outbreaks have foiled two previous reintroduction attempts, as well as causing the extinction of at least one wild population (Scheepers \& Venzke, 1995; Woodroffe et al., 1997; Mills et al., 1998). Potential release sites that contain, or are adjacent to, areas with high densities of domestic dogs should therefore be avoided, and domestic dogs should not be brought on to reintroduction sites. Similar measures were required to protect reintroduced black-footed ferrets Mustela nigripes from canid diseases (Williams et al., 1992). At present, there is no protocol for vaccinating wild dogs against rabies that is known to provide protection; research is urgently needed to establish protocols for field use (Woodroffe et al., 1997). However, because rabies vaccination appears not to be harmful, it would be appropriate to give inactivated rabies vaccine to wild dogs intended for release. Preliminary research indicates that multiple doses are likely to be necessary (Visee, 1996; Woodroffe et al., 1997; G. Thomson, pers. comm.). 
Are there release sites which meet these criteria?

As discussed above, reintroduction is most needed to re-establish extirpated wild dog populations in West and central Africa. However, we are not aware of any reserves in this area likely to prove suitable for wild dog reintroduction, primarily because most of the reserves are too small. At 11,500 sq km, Comoé National Park in Côte d'Ivoire would be large enough to support a wild dog population but it contains very few hyaenas and lions, suggesting either that predators have not been tolerated or that prey have been severely depleted (Woodroffe et al., 1997).

In East Africa, reintroduction might be considered in the Serengeti-Masai Mara ecosystem on the Kenya-Tanzania border, where the resident wild dog population became extinct in 1991 (Woodroffe et al., 1997). At approximately $25,000 \mathrm{sq} \mathrm{km}$, the Serengeti ecosystem should be large enough to support a viable wild dog population; indeed, some viability analyses of this population suggested that extinction was unlikely in the absence of some major external catastrophe (Burrows et al., 1994). However, there are two obstacles to wild dog reintroduction in the SerengetiMara. First, the disease threat, which contributed to the extinction of the original population, has not been removed. The dynamics of disease within the ecosystem remain poorly understood, and plans to control rabies and canine distemper by mass vaccination of domestic dogs in the surrounding area have been partially suspended (Anon., 1996; G. Kamau, pers. comm.). Second, at present there is no identified source of wild dogs with the appropriate genotype; the former population carried a unique genotype not yet found in other wild dog populations (Girman et al., 1993). Dispersing groups have been seen in the park since extinction of the original population, so it is possible that recolonization might occur naturally (Woodroffe et al., 1997).

Within southern Africa, wild dog reintroduction might be considered in Etosha National Park, Namibia. Three past attempts to reintroduce wild dogs to Etosha have failed, but this was primarily because captive-bred animals were used (Scheepers \& Venzke, 1995). At 21,350 sq km, Etosha National Park should be large enough to support a viable wild dog population but reintroduction efforts should proceed with caution because the reason for the extinction of the original population remains unknown. Rabies foiled one past reintroduction attempt, so future releases might be better delayed until the establishment of a reliable protocol for rabies vaccination of wild dogs.
Wild dog reintroduction is also being considered in a number of sites in South Africa, in the course of establishing the proposed wild dog metapopulation (Mills et al., 1998; Woodroffe, 1998). This programme depends upon intensive management of tiny populations in a network of fenced private reserves. This approach is probably unsuitable for other African countries, which contain few, if any, fenced reserves, and attract little tourist revenue to fund such releases. Despite its limitations, however, in the future such an approach may be the only option for wild dog conservation in highly fragmented habitats.

\section{Conclusions}

At present, reintroduction has limited value as a tool for the conservation of African wild dogs. Recent releases in southern Africa suggest that wild dog reintroduction is probably technically possible. However, population recovery is most needed in West and central Africa, where the potential for reintroduction is severely limited by a lack of suitable release sites, as well as by a lack of animals genetically suitable for release. The reintroduction programme planned for South Africa will be of great benefit in promoting national recovery of wild dog populations, but has relatively little value on a continental scale because it depends upon a system of land ownership and land use, and on a level of financial support, which are not represented in other regions of Africa. We therefore conclude that, at present, protection of the wild dog populations that remain across Africa represents a much better conservation investment than any attempt to re-establish populations that have been extirpated.

\section{Acknowledgements}

Much of the information presented in this paper was collated in preparing the IUCN Status Survey and Conservation Action Plan for the African wild dog (Woodroffe et al., 1997). We would like to thank IUCN for permission to cite this information, and Scott Creel, John Fanshawe, Jack Grisham, Joe van Heerden, Markus Hofmeyr, David Macdonald, Ant Maddock, Gus Mills and Lue Scheepers for comments on the relevant parts of the Action Plan, as well as Sarah Durant and an anonymous referee for comments on the manuscript. R.W. also thanks Fauna \& Flora International and the Endangered Wildlife Trust for support in attending the Population and Habitat 
Viability Analysis Workshop for southern African wild dogs held in Pretoria in 1997.

\section{References}

Anon. (1996) Dogs to be vaccinated around Serengeti. Oryx, $30,169$.

Beck, B.B., Rapaport, L.G., Stanley Price, M.R. \& Wilson, A.C. (1994) Reintroduction of captive-born animals. In Creative Conservation-Interactive Management of Wild and Captive Animals (eds P. J. S. Olney, G. M. Mace and A. T. C. Feistner). Chapman \& Hall, London.

Brewer, B.A. \& Rhodes, S. (1992) International Studbook for the African Wild Dog, Lycaon pictus. Chicago Zoological Society, Chicago.

Burrows, R., Hofer, H. \& East, M.L. (1994) Demography, extinction and intervention in a small population: the case of the Serengeti wild dogs. Proceedings of the Royal Society of London B, 256, 281-292.

Carbyn, L.N., Armbruster, H.J. \& Mamo, C. (1994) The swift fox reintroduction program in Canada from 1983 to 1992. In Restoration of Endangered Species-Conceptual Issues, Planning and Implementation (eds M. L. Bowles and C. J. Whelan). Cambridge University Press, Cambridge.

Childes, S. (1988) Can reintroduction save the wild dog? Zimbabwe Wildlife, 51, 27-29.

English, R.A., Stalmans, M., Mills, M.G.L. \& van Wyk, A. (1993) Helicopter assisted boma capture of African wild dogs, Lycaon pictus. Koedoe, 36, 103-106.

Fitzjohn, T. (1995) African Hunting Dog (Lycaon pictus) Capture and Translocation. Unpublished report. Ministry of Tourism, Natural Resources \& Environment, Tanzania.

Frame, L.H. \& Fanshawe, J.H. (1990) African Wild Dog Lycaon pictus: a Survey of Status and Distribution 1985-88. Unpublished report. Canid Specialist Group, Oxford University.

Fritts, S.H., Bangs, E.E., Fontaine, J.A., Johnson, M.R., Phillips, M.K., Koch, E.D. \& Gunson, J.R. (1997) Planning and implementing a reintroduction of wolves to Yellowstone National Park and central Idaho. Restoration Ecology, 5, 7-27.

Fritts, S.H., Paul, W.J. \& Mech, L.D. (1985) Can relocated wolves survive? Wildlife Society Bulletin, 13, 459-463.

Girman, D.J., Wayne, R.K., Kat, P.W., Mills, M.G.L., Ginsberg, J.R., Borner, M. et al. (1993) Molecular-genetic and morphological analyses of the African wild dog (Lycaon pictus). Journal of Heredity, 84, 450-459.

Griffith, B., Scott, J.M., Carpenter, J.W. \& Reed, C. (1989) Translocation as a species conservation tool: status and strategy. Science, 245, 477-480.

Henshaw, R.E., Lockwood, R., Shideler, R. \& Stephenson, R.O. (1979) Experimental release of captive wolves. In The Behavior and Ecology of Wolves (ed. E. Klinghammer). Garland STPM Press, New York.

IUCN (1995) IUCN Guidelines for Reintroductions. IUCN, Gland, Switzerland.

Kleiman, D.G. (1989) Reintroduction of captive mammals for conservation. BioScience, 39, 152-161.
Kleiman, D.G., Stanley Price, M.R. \& Beck, B.B. (1994) Criteria for reintroductions. In Creative Conservation-Interactive Management of Wild and Captive Animals (eds P. J. S. Olney, G. M. Mace and A. T. C. Feistner). Chapman \& Hall, London.

Maddock, A. (1992) Reintroduction of Wild Dogs to Hluhluwe and Umfolozi Game Reserves, South Africa. Unpublished report. Workshop on the Conservation and Recovery of the African Wild Dog, Lycaon pictus, Arusha, Tanzania. Natal Parks Board, Pietermaritzburg, Natal, South Africa.

Maddock, A. (1996) Motivation for Introduction of Additional Wild Dogs to Hluhluwe-Umfolozi Park. Unpublished report. Natal Parks Board, Pietermaritzburg, Natal, South Africa.

Maddock, A.H. \& Mills, M.G.L. (1994) Population characteristics of the African wild dogs Lycaon pictus in the eastern Transvaal lowveld, South Africa, as revealed through photographic records. Biological Conservation, 67, $57-62$.

Mills, M.G.L., Ellis, S., Woodroffe, R., Maddock, A., Sander, P., Rasmussen, G. et al. (1998) Population and Habitat Viability Assessment for the African Wild Dog (Lycaon pictus) in Southern Africa. IUCN/SSC Conservation Breeding Specialist Group, Apple Valley MN, USA.

Mills, M.G.L. \& Hofer, H. (1998) Hyaenas-Status Survey and Conservation Action Plan. IUCN, Gland, Switzerland.

Nowell, K. \& Jackson, P. (1996) Wild Cats-Status Survey and Conservation Action Plan. IUCN, Gland, Switzerland.

Phillips, M. (1995) Conserving the red wolf. Canid News, 3, 13-17.

Roy, M.S., Girman, D.J., Taylor, A.C. \& Wayne, R.K. (1994) The use of museum specimens to reconstruct the genetic variability and relationships of extinct populations. Experientia, 50, 551-557.

Scheepers, J.L. (1992) Reintroductions in Etosha, Namibia. Unpublished report. Workshop on the Conservation and Recovery of the African Wild Dog, Lycaon pictus, Arusha, Tanzania. Canid Specialist Group, Oxford University.

Scheepers, J.L. \& Venzke, K.A.E. (1995) Attempts to reintroduce African wild dogs Lycaon pictus into Etosha National Park, Namibia. South African Journal of Wildlife Research, 25, 138-140.

Stanley-Price, M.R. (1988) Animal Reintroductions: The Arabian Oryx in Oman. Cambridge University Press, Cambridge.

Visee, A.M. (1996) African Wild Dogs, Mkomazi Game Reserve, Tanzania-Veterinary Report. Unpublished report. George Adamson Wildlife Preservation Trust, the Netherlands.

Weise, T.F., Robinson, W.L., Hook, R.A. \& Mech, L.D. (1979) An experimental translocation of the Eastern timber wolf. In The Behavior and Ecology of Wolves (ed. E. Klinghammer). Garland STPM Press, New York.

Williams, E.S., Thorne, E.T., Kwiatkowski, D.R. \& Oak-leaf, B (1992) Overcoming disease problems in the black-footed ferret recovery programme. Transactions of the North American Wildlife and Natural Resources Conference, 57, 474-485.

Woodroffe, R. (1998) The African wild dog-conservation planning for Southern Africa. Oryx, 32, 13-14.

Woodroffe, R. \& Ginsberg, J.R. (1998) Edge effects and the extinction of populations inside protected areas. Science, 280, 2126-2128. 
Woodroffe, R. \& Ginsberg, J.R. (1999) Conserving the African wild dog, Lycaon pictus. I. Diagnosing and treating causes of decline. Oryx, 33, 134-144.

Woodroffe, R., Ginsberg, J.R. \& Macdonald, D.W. (1997) The African Wild Dog: Status Survey and Conservation Action Plan. IUCN, Gland, Switzerland.

Wyoming District Court, USA (1997) Wyoming Farm Bureau et al., James $R$. and Cat D. Urbikit, National Audubon Society et al. vs Bruce Babbit, in his official capacity as Secretary of the Department of Interior, et al. Civil Case No 94-CV-286-D. http://www.defenders. org/ynpdec1.html

\section{Biosketches}

Rosie Woodroffe is a lecturer in Conservation Biology at the University of Warwick, UK. Much of her research focuses on the resolution of conflict between predators and people, encompassing both conservation biology and wildlife management. She and Joshua Ginsberg are co-authors of The African Wild Dog: Status Survey and Conservation Action Plan published by IUCN.

Joshua Ginsberg carried out a 5-year field study of wild dogs in and around Hwange National Park, Zimbabwe, before becoming Director of the Asia Program for the Wildlife Conservation Society, based in New York. He oversees 110 projects in 15 Asian countries on topics ranging from the taxonomy and ecology of frogs in the highlands of Papua New Guinea to community-based approaches to conservation in Laos. 